\title{
Locally Artinian Supplemented Modules
}

\section{BURCU TURKMEN ${ }^{1}$ and Yavuz Şahin ${ }^{1}$}

${ }^{1}$ Amasya University

November 26, 2020

\begin{abstract}
In this paper, we introduce notions of RLA-local modules and locally artinian supplemented modules which are proper generalizations as notions of strongly local modules and ss-supplemented modules, respectively and we study some properties of these module. In particular, we give a characterization of semi perfect rings and left perfect rings.
\end{abstract}

\section{Hosted file}

Locally Artinian Supplemented Modules.pdf available at https://authorea.com/users/360031/ articles/495432-locally-artinian-supplemented-modules 